\title{
Assessment on the Determinant and Impact of Coffee Production on House Hold Income (In Case of Anfilo Woreda)
}

\author{
Habtu Nibret ${ }^{1}$, Getnet Ayalew ${ }^{2}$ \\ ${ }^{1}$ Department of Economics, Debark University, Gondar, Ethiopia \\ ${ }^{2}$ Department of Marketing Management, Debark University, Gondar, Ethiopia
}

Email address:

habtunib@gmail.com (H. Nibret)

To cite this article:

Habtu Nibret, Getnet Ayalew. Assessment on the Determinant and Impact of Coffee Production on House Hold Income (In Case of Anfilo Woreda). Journal of World Economic Research. Vol. 9, No. 1, 2020, pp. 58-65. doi: 10.11648/j.jwer.20200901.19

Received: December 17, 2019; Accepted: February 14, 2020; Published: March 6, 2020

\begin{abstract}
Coffee is increasingly becoming a part of Western culture, it is most likely that they will not think of the more than "25 million people around the world [that] base their livelihoods on its production". Coffee is the major agricultural export crop, providing currently $35 \%$ of Ethiopia's foreign exchange earnings. The coffee sub-sector is also important in terms of providing income for a large number of households. This study assessed the impact of coffee production and household income in Anfilo wereda Oromiya regional State. The study also investigated factors influencing coffee production and incomes of household. The study followed a multistage random sampling procedure. Data collected from 116 sample households was used in this study. Descriptive statistics were employed and logit model (logistic regression) was used to identify factors influencing coffee production and sample household income.
\end{abstract}

Keywords: Coffee, Logistic Regression, Heteroskedasticity, Foreign Exchange, Ethiopia

\section{Introduction}

Coffee is increasingly becoming a part of Western culture; for many it has become a daily routine and coffee shops are now a common social meeting ground. Since coffee shops are springing up at every half block in one's local downtown, it may not be surprising that coffee has become the second largest traded commodity next to oil [1]. As the consumer steps up to the register and orders their four-dollar latte, it is most likely that they will not think of the more than " 25 million people around the world [that] base their livelihoods on its production" [2]. The producers of these coffee beans are often small-scale farmers who are reliant on faceless consumers, large corporations and an ebbing market for their income and resources. With coffee being one of the world's most traded markets, it is important for both consumers and producers to understand the impact the production of coffee is having on the farmers at a local level. In reality, as globalization expands so does the gap between coffee farmer and consumer. Even movements that seek to remove this veil, such as the Fair Trade Organization, are perceived by the consumer to only be a more expensive pound of coffee with a different label.

In addition, the conditions of coffee farmers varies from region to region, but generally the farmers are "at a disadvantage in global markets and often receive low prices for their products". The farmers have to not only deal with the unpredictable force of Mother Nature, but also with "the boom and bust cycles in commodity prices," Limited economic resources and political control. Often the analysis of the coffee market can be sweeping and focused on economic efficiency rather than the local impacts of market changes which often result in "the marginalization of small-scale farmers, increased environmental degradation, and overall rural decline and poverty" [2]. With market shifts, not only are the changes seen on an economic level, but the farmers' lives are also changed at the local level. Coffee farmers must consider the value of their crops since their access to education, health care, meals and their total livelihood relies on their crop's production.

More genetically diverse strains of $C$. Arabica exist in Ethiopia than anywhere else in the world, which has lead botanists and scientists to agree that Ethiopia is the centre for 
origin, diversification and dissemination of the coffee plant [3; 4]. The estimated coffee production area ( $2 \%$ of total cultivated land) in Ethiopiais measured in the range of 320,000 to 700,000 ha [5], though potentially there exist about 6 million ha cultivable land suitable for coffee production. The coffee cultivation takes place from $900 \mathrm{~m}$ in Magi (Kaffa) to $2300 \mathrm{~m}$ above sea level in Gore (Illubabor) [4], even if the optimum productive plantations are located between 1500 to $1800 \mathrm{~m}$ above sea level (Paulos, 1994). The dominant coffee growing soil types are Nitosol (25\%), Acrisol (17\%), and Luvisol (14\%) [6]. The soil texture class is varying from clay $(13 \%)$, loamy clay $(29 \%)$, silty clay $(29 \%)$, to sandy clay $(22 \%)$ in relative proportion. The soil $\mathrm{pH}$-value ranges from 4.4 to 6.8. Diurnal and seasonal fluctuations in temperature $\left(14\right.$ to $\left.30^{\circ} \mathrm{C}\right)$, relative humidity (43 to $85 \%$ ) and heavy rainfall (1000 to $2000 \mathrm{~mm}$ ) are very frequent in different coffee growing zones [7].

The forest and semi-forest (10\%), garden coffee (85\%), and plantation coffee $(5 \%)$ are the major conventional production systems. There are variations in genotypes, eco-physiology and the biosphere of coffee under different production systems. Plantation coffee can be regarded as an Intensive traditional agro forestry system. The small-scale farmers are the major producers, whereby about 140 local coffee land races known to grow as garden with owing on average 0.5 ha of coffee farming systems [8].

Coffee is the major agricultural export crop, providing currently $35 \%$ of Ethiopia's foreign exchange earnings, down from $65 \%$ a decade ago because of the slump in coffee prices since the mid-1990's in a country where about $44 \%$ of the population is under poverty [9]. Ethiopia's most important export crop contributing $41 \%$ of the country's foreign currency income was coffee. Coffee cultivation plays a vital role both in the cultural and social-economic life of the nation. It is the most important export commodity for Ethiopia agriculture and plays an important role in the country's economy. This is especially true for the Oromia, South Nations and Nationalities of people (SNNP) and Gambella Regional States.

\subsection{Statement of the Problem}

The coffee sub-sector is very important to the Ethiopian economy, and generated about 335 million USD or $41 \%$ of the foreign exchange earnings in 2005. The coffee sub-sector is also important in terms of providing income for a large number of households: it is estimated that between 7.5 and 8 million households depend on coffee for a considerable share of their income, and provides jobs for many more people in coffee-related activities (e.g. coffee processing, transporting or marketing). It is estimated that the sub-sector impacts on approximately $15 \%$ of the population, and around $20 \%$ of the land area [10].

In Ethiopia, coffee is primarily cultivated by smallholders, either cultivating coffee on their own farms or picking semi-wild/wild coffee. Of the estimated 600,000 hectares of land cropped with coffee, over half is semi-forest/forest, or semi-wild/wild land. Approximately 235,600 hectares are under smallholder cultivation, ('garden' or 'cottage' coffee), which is generally inter-cropped with food staples.
Smallholder coffee accounts for approximately $95 \%$ of total coffee production. There are about 20,000 hectares of plantation coffee, consisting mainly of state farms, but increasingly also of plantations under private ownership [10]

Coffee growers in Ethiopia have been exposed to price fluctuations and impacts of unpredictable and uncontrollable shocks. Despite some improvement of producer prices in the past two decade, domestic and world coffee prices have declined and remained very low for much of the late 1990s and early 2000s. The effect of this price decline was manifested in increasing poverty among coffee growers, who previously were able to reap good benefits from their coffee sales. At household level the impact of depressed prices has been considerable, leading to distress sales of assets such as cattle, or to uprooting coffee plants and replacing them with annual food crops [11] or cash crops such as Chat 1 . Other strategies included giving up traditional shade coffee production to create space for inter cropping and income diversification [10].

Coffee production is a very important issue and is crucial for household income generation in Ethiopia. As a result only few researchers are available on the study of the subject coffee production around the study area. Assessments made by independent institutions and researchers do not yet given sufficient insight into the practice of impact of coffee production on household income in Qellem wollega, zone oromiya region.

Therefore, the study attempts to assess the impact of coffee crop production on household income in Anfilo woreda, Qellem wollega zone in line with the implementation of woreda coffee production strategy in Oromia Region by selecting one local government administration, i.e., Anfilo woreda.

\subsection{Objective of the Study}

\subsubsection{General Objective}

The general objective of the study is to assess the determinant and impact of coffee production on house hold income.

\subsubsection{Specific Objectives}

Identifying factors affecting coffee production in the study area.

Investigating the role of coffee production on the household income of the study area.

\subsection{Basic Research Questions}

1. What are factors affecting coffee production in the study area?

2. What is the role of coffee production on household income?

\section{Research Methodology}

\subsection{Description of Study Area}

The study was carried out in Anfilo woreda, Oromia National Regional State of Ethiopia (Figure 1). The study 
area is located between $8^{\circ} 40^{\prime} 0^{\prime \prime}$ to $9^{\circ} 10^{\prime} 0^{\prime \prime}$ North latitude and $35^{\circ} 10^{\prime} 0^{\prime \prime}$ to $35^{\circ} 20^{\prime} 0^{\prime \prime}$ East longitude (AWRCO, 2017). The administrative center of the woreda is Mugi is, $42 \mathrm{~km}$ away from Dambi Dolo (Zonal Administrative town), and $602 \mathrm{~km}$ far from Addis Ababa (country capital)..

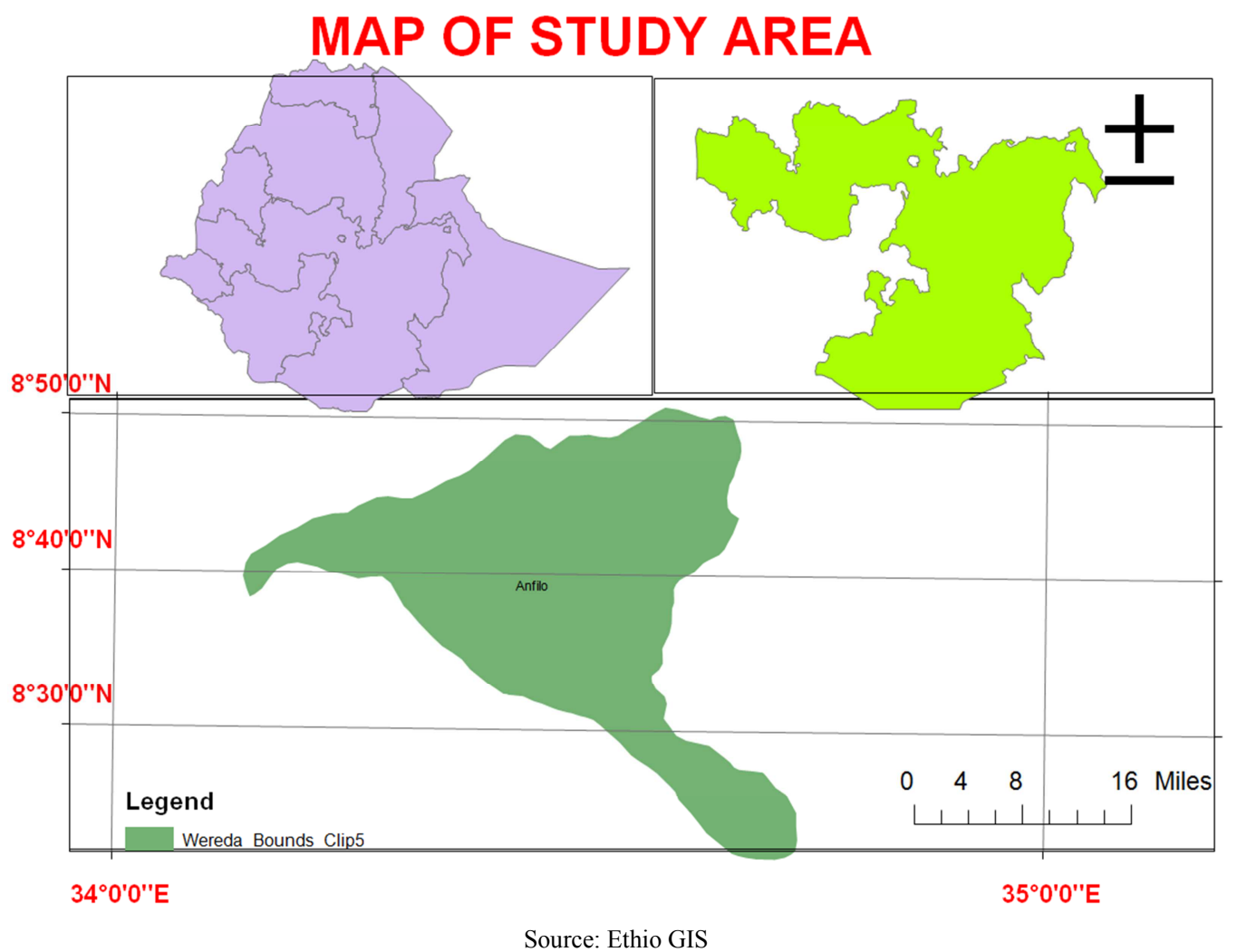

Figure 1. Map of the Study Area.

Climate of the Study Area

It has a monomials rain fall pattern, which is the characteristic feature of whole western Ethiopia. This woreda is the wettest woreda with the annual rainfall ranges from minimum rainfall of $1049 \mathrm{ml}$ and Maximum rainfall $1955 \mathrm{ml}$ ).
Maximum temperature is $32.9^{\circ} \mathrm{C}$ and minimum temperature is $11^{\circ} \mathrm{c}$ respectively. According to Anfilo agricultural and rural development office (2017), has two agro-ecological zone, namely kola $(40 \%)$, and woinadega $(60 \%)$.

\section{rainfall}

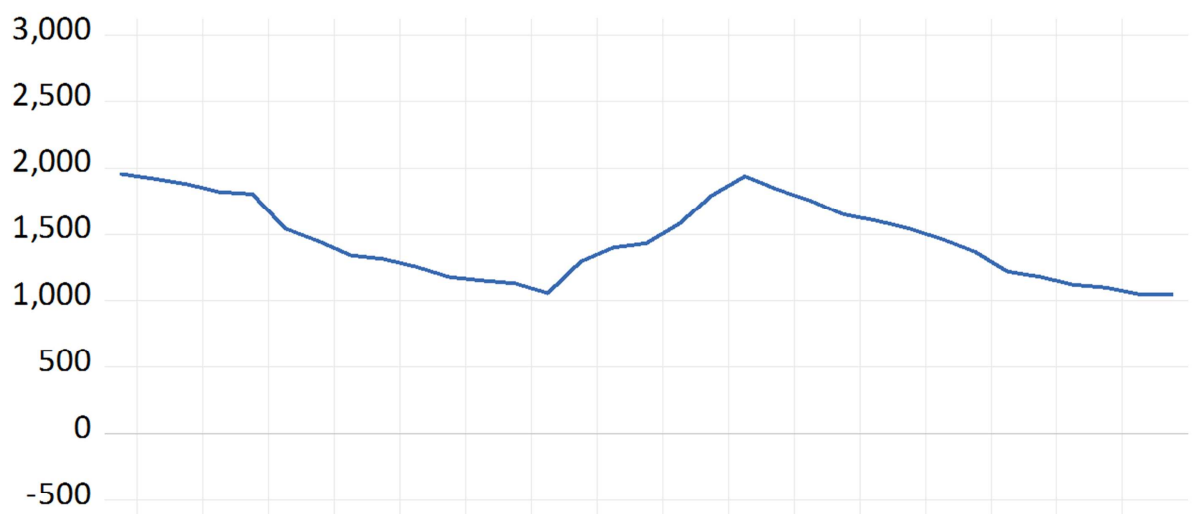

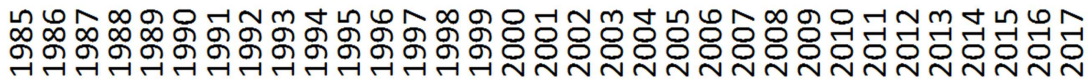

Source: (AWARDO, 2016)

Figure 2. Annual rainfall in Anfilo Woreda. 
36

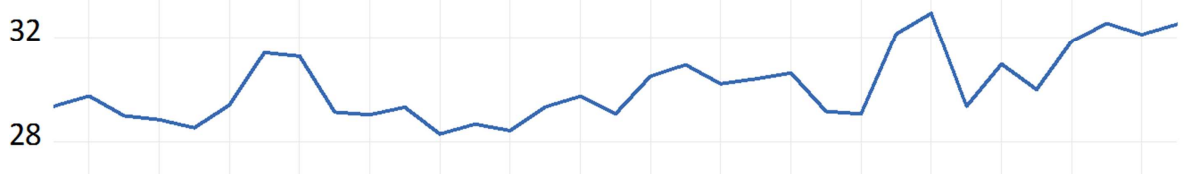

24

20

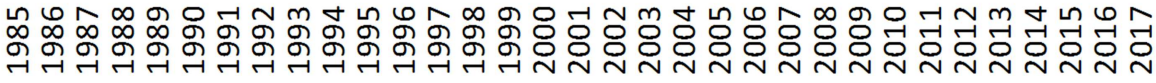

Source: (AWARDO, 2016).

Figure 3. Annual maximum temperatures in Anfilo Woreda.

$\min t$

40

30

20

10

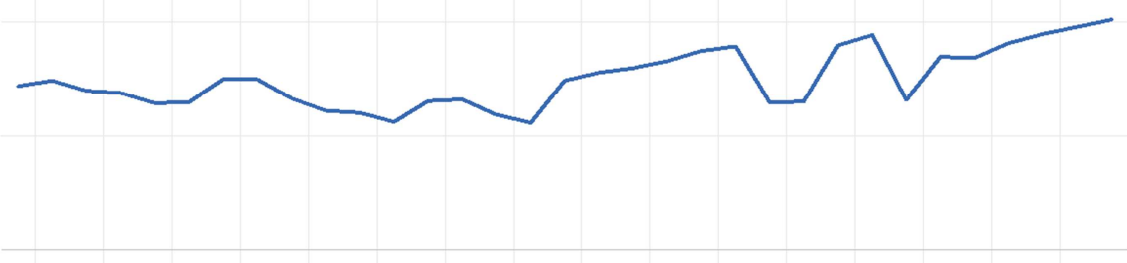

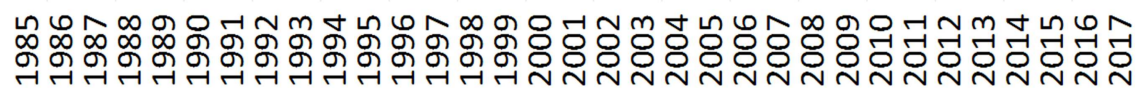

Source: (AWARDO, 2016).

Figure 4. Annual minimum temperatures in Anfilo Woreda.

\subsection{Data Type, Source, Collection Methods and Research Design}

The most effective evaluation research is the one that combines qualitative and quantitative components. Thus, the research strategies employed in this study combine both qualitative and quantitative methods. Qualitative method is used to capture data pertaining farmers attitude and willingness to adopt sowing in line using semi-structured questionnaire. Quantitative data on demographic characteristics and other basic information is collected from sample households using structured questionnaire. Focused group discussion and key in formant data collection tools was also be used. Secondary data was collected from relevant literatures, reports of Agricultural and Rural development offices and other publications.
This study is an explanatory type of study; since it explains the relationship between income of household and the various explanatory variables. To achieve the pre - stated objective of the study, both primary and secondary data will be uses. Moreover, the researcher also used both quantitative and qualitative data. Quantitative data will be obtains from the households via questionnaire, which was designed by the author with the support and supervision of co-advisors and the qualitative data were taken from focus group discussion and agricultural staff through semi - structured interview in order to triangulate the analysis.

\subsection{Sampling}

The third stage, the representative sample households from the total household has been selected using [12] formula

The formula given as 
$\mathrm{n}=\frac{Z^{2} P \cdot Q \cdot N}{e^{2}(N-1)+Z^{2} \cdot P \cdot Q}$

Where, $\mathrm{n}=$ sample size

$\mathrm{Z}=$ value of standard variant at $95 \%$ confidence level (1.96)

$\mathrm{P}=$ sample proportion $0.03=3 \%$

$\mathrm{Q}=1-\mathrm{p}$

$\mathrm{e}=$ the estimation allowable error $(0.03)=3 \%$

$\mathrm{N}=$ number of households (3725)

$$
\begin{gathered}
\mathrm{n}=\frac{1.96^{2} \cdot 0.03 \cdot 0.97 \cdot 3725}{(0.03)^{2}(3725-1)+1.96^{2} \cdot 0.03 \cdot 0.97} \\
\mathrm{n}=\frac{416.419836}{3.46339056}=120
\end{gathered}
$$

A total of 120 household heads had sampled for a questionnaire survey from the two rural kebele administrations using systematic random sampling technique on the basis of probability proportional to size.

\subsection{Econometrics Model}

To explain the observed variation in income practice, logistic regression model in which the dependent variable coffee production is regressed as a function of the explanatory variables demographic, social - cultural, institutional and economic factors will uses. The households' response whether has impact on his income or not is outlined as a binary-choice model.

As outlined in [13] and [14], logit or probit models are widely applied to analysis for a limited dependent variable which has a binary outcome. Despite this, [14] argues that although both models result with similar outputs, the logit model is easier in estimation. Thus, binary logit model was employed in this study. To analyze the factors that determine the impacts of coffee production at household level, households was classified in to two categories as the one who has impacts on his income and otherwise.

Model Specification

Binary Logit model

Following the concept of the model from [14] and [13], the logit model for coffee production practice at household level determinants can be specified as below:

$$
\begin{gathered}
P(Y i=1)=\frac{1}{1+e^{-(B i X i)}} \\
P(Y i=1)=\frac{1}{1+e^{-Z i}}
\end{gathered}
$$

Where: $\mathrm{P}(\mathrm{Yi}=1)$ is the probability that a household has impact on his income, $\mathrm{Zi}=$ the function of a vector of explanatory variables), e- represents the base of natural logarithms and equation (2) is the cumulative distribution function. If $\mathrm{P}(\mathrm{Yi}=1)$ is the probability of having income effect, then $1-\mathrm{P}(\mathrm{Yi}=1)$ represents the probability that the household has no impact on his income and is expressed as:

$$
\begin{gathered}
1-P(Y i=1)=1-\frac{1}{1+e^{-Z i}}=\frac{1}{1+e^{Z i}} \\
\frac{P(Y i=1)}{1-P(Y i=1)}=\frac{1+e^{Z i}}{1+e^{-Z i}}=e^{Z i}
\end{gathered}
$$

Equation (4) simply is the odds ratio, the ratio of the probability that a household will be has impact on his income to the probability that it will be has no impact on his income. Taking the natural log of equation (4), we obtain

$$
L i=\ln \left(\frac{P(Y i=1)}{1-P(Y i=1)}\right)=Z i
$$

Where: $\mathrm{Li}$ is the $\log$ of the odd ratio which is not only linear in the explanatory variables but in the parameters also. Thus, introducing the stochastic error term (Ui), the logit model can be written as

$$
Z i=\beta \text { o }+\beta 1 X 1+\beta 2 X 2+\beta 3 X 3+\ldots \beta i X i
$$

Where

$\mathrm{X}$ 's $=$ are explanatory variables that determines the household level of income system,

$\beta_{0}$ is the constant term and $\beta$ 's are coefficients to be estimated.

\section{Result and Discussion}

\subsection{Main Factors That Affects Participation in Coffee Production (Binary Logit Model)}

\begin{tabular}{|l|l|l|l|l|}
\hline variable & coefficient & Std.error & Z-statistic & prob \\
\hline MDMY2 & 0.6986 & 3.9220 & 0.1781 & 0.0086 \\
\hline NEARDMY2 & 0.1536 & 1.8748 & -0.0819 & 0.0346 \\
\hline AFDMY2 & 0.3144 & 1.8440 & 0.1705 & 0.0445 \\
\hline AGODMY2 & -0.5379 & 1.7581 & -0.3059 & 0.7596 \\
\hline ADMY2 & 1.0987 & 1.6869 & -0.6513 & 0.0148 \\
\hline ACDMY2 & 2.3369 & 2.2075 & 1.0586 & 0.0297 \\
\hline AADMY2 & -1.0644 & 1.8190 & -0.5853 & 0.5583 \\
\hline A & 0.9771 & 0.3354 & 2.9126 & 0.0036 \\
\hline LF & -0.3559 & 0.3166 & -1.1242 & 0.2609 \\
\hline CL & 1.1736 & 1.3636 & 0.8606 & 0.0894 \\
\hline RDMY2 & -1.1259 & 4.2082 & -0.2675 & 0.7890 \\
\hline WDDMY2 & -1.6923 & 2.5219 & -0.6710 & 0.1021 \\
\hline FDMY2 & 0.6310 & 2.0915 & -0.3016 & 0.0628 \\
\hline C & -28.9524 & 10.3478 & -2.7979 & 0.0051 \\
\hline
\end{tabular}

Source: computed from own survey, 2018.

Figure 5. Results of logistic regression model.

The binary logistic regression model was used to establish the relationships between Choice of adaptation strategies and a set of predictor variables. It was selected as it can be used with continuous, discrete and dichotomous variables mixed together [15]. Thirteen predictor variables were selected to explain the dependent variable (choice of impact on their income). Out of the total predictor variables, eight variables were significant at $1 \%, 5 \%$ and $10 \%$ probability levels. In this sub section, we treat results concerning coffee crop income at household level as well as the socio economic, demographic and other factors that affect the coffee crop income behavior of households. We used logit model of estimation to figure out factors having a certain sort of relationship to the program participants. The output for the logit /participation/ equation shows that eight variables determine the probability of participating in coffee production. These are Age of the household head (A), sex of household head (Mdmy2), nearer to training center (NEAR dmy2), access of fertilizer 
(AFdmy2), adaptation of coffee production technology (ADdmy2), access of credit (ACdmy2), cultivated land size (CL), source of income (Fdmy2) and the constant term.

Sex of Households

Sex of the household heads is an important variable influencing for participation in coffee production and income of sample household heads. When the participation of male increases by one unit causes the income of the household head will be men probably increase by 0.69 than increase the participation of female. This is because women may have limited access to information and other resources due to traditional social barriers.

Nearness to farmers training center

This is exclusionary variables that can make the Decision Equation better. The logistic regression result explains that there is a positive relation between nearness to farmer training center and coffee production as well as income of the household heads.

\section{Access fertilizer}

This variable showed a positive relationship with participation coffee production and income of household heads. It is statistically significant at five percent probability level. The main reasons for possible positive factor are when farmers getting more fertilizer can increases coffee production and directly affect the income of the participant household heads.

\section{Adaptation of coffee production technology}

The logistic regression result shows that the is a positive relationship between adaptation of coffee production technology and coffee production as well income of the household heads, and the variable is statistically significant at five percent probability level. The possible positive result is due to the link that adopting new coffee production technology like can always result in improving coffee production and directly affects income of the participant household heads.

Accessibility of Credit

As can be seen in the above table about 63 percent of respondents household heads who engaged in coffee production have access of credit, while about 37 percent of engage in coffee production have not access of credit institutions. According to FGDs and Key informant interviews the main sources of credit for adapt climate variability in the study area were OCSI, Ikub and Iddir.

Age of the household heads

Age household heads is an important variable influencing for participation in coffee production and income of sample household heads. For the purpose of this research it is a continuous variable. The result of logistic regression model shows that there is a direct relationship between age of the household heads and coffee production as well as income of the household heads and the variable is significant at one percent probability levels.

Cultivated land size

This variable shows that there is a positive relationship between cultivated land size and coffee production as well as income of the household heads and statistically significant at ten percent probability level. For this study cultivated land is a continuous variable and measured by hectare.

\section{Source of household heads income}

The regression indicates that there is a positive relationship between farm income and coffee production hence income of household heads. The variable is statistically significant at ten percent probability level.

\subsection{Measuring Goodness of Fit to the Model}

There are two very different approaches to Measuring Goodness of Fit in logistic regression the Model. One is to get a statistic that measures how well you can predict the dependent variable based on the independent variables. It refers to these kinds of statistics as measures of predictive power. Typically, they vary between 0 and 1 , with 0 meaning no predictive power whatsoever and 1 meaning perfect predictions. Predictive power statistics available in PROC LOGISTIC include R-square, the area under the ROC curve, and several rank-order correlations. Obviously; the higher the better but there is rarely a fixed cut-off that distinguishes an acceptable model from one that is not acceptable.

The other approach to evaluating model fit is to compute a goodness-of-fit statistic. With PROC LOGISTIC, you can get the deviance, the Pearson chi-square, or the Hosmer-Lemeshow test. These are formal tests of the null hypothesis that the fitted model is correct, and their output is a $p$-value--again a number between 0 and 1 with higher values indicating a better fit. In this case, however, a $p$-value below some specified @ level (say,.05) would indicate that the model is not acceptable.

A Receiver Operating Characteristic Curve (ROC) is a standard technique for summarizing classifier performance over a range of trade-offs between true positive (TP) and false positive (FP) error rates [16]. ROC curve is a plot of sensitivity (the ability of the model to predict an event correctly) versus 1-specificity for the possible cut-off classification probability values $\pi 0$. For logistic regression you can create a $2 \times 2$ classification table of predicted values from your model for your response if or 1 versus the true value of $y=0$ or 1 .

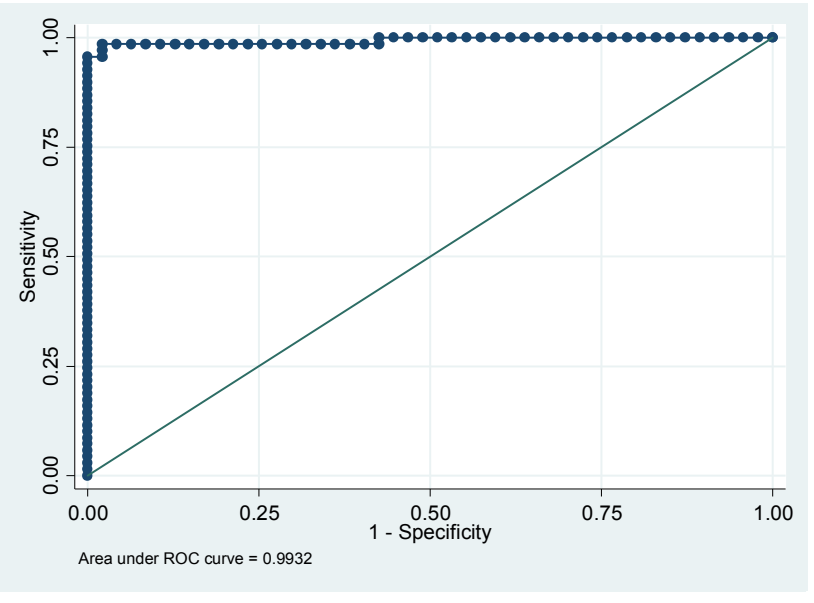

Source: computed from own survey, 2018.

Figure 6. ROC Curve.

From the above figure we can observe that ROC curve 
equals to 0.99 which near to one or perfection. This means that the powers of prediction of the explanatory very strong and the model are good.

McFadden R-squared: The result of $\mathrm{R}^{2}$ shows that the dependent variable is highly explained by the independent variables. The result explained that $88.7 \%$ of the variation of dependent variable is because of the independent variable. This means that most of variation of the income change is comes from the above explanatory variable.

\section{Conclusions and Recommendation}

This section presents brief conclusion depending on findings and discussed on the pervious chapter and recommendation for expanding coffee production as well as increasing household heads income.

\subsection{Conclusions}

This study assesses the impacts and determinants of coffee production on income of household in the case of Anfilo Woreda, Kellem Wollega Zone Oromia regional state. The binary logistic regression model was used for the estimation. Further, diagnostic test for pre estimation and ROC as well as good ness of fit is applied for checking the model is fitted or not.

The dependent variable is (income of household heads) in Anfilo wereda is affects by different explanatory variables (demographic, social and economic factors); These are Age of the household head (A), sex of household head (Mdmy2), nearer to training center (NEAR dmy2), access of fertilizer (AFdmy2), adaptation of coffee production technology (ADdmy2), access of credit (ACdmy2), cultivated land size (CL), source of income (Fdmy2). These variables are statistically significant ay 1,5 , and 10 percent probability level. Major findings of the study are presented below.

The results of diagnostic test shows that there is no problems of multicolinerity, hetroskedacticity and ramset RESET tests of the fitted values so we conclude that there is no problem in the model the result is putted in the appendices part.

\subsection{Recommendation}

The previous section has presented the summary of major findings of the study. Based on the findings the following recommendations are made for policy purposes;

i. The local as well as the regional or federal government can expand farmers training center as much as possible to approach the farmer. Nearer farmer training center have positive impacts on coffee production hence income of household heads.

ii. The government must be providing high volume of fertilizer or increase access of fertilizer to the farmer in order to improve production and productivity of the coffee production. When production and productivity increase there is a direct impact on income and livelihood of the household heads of coffee producers. iii. The coffee producers also adopt coffee production technology in order to increase their production and productivity. When farmers use technology for coffee production their income and livelihood can be improved. The concerned body may be agricultural office can give some knowhow about how to use and use of technological advancement.

iv. The local government can create a connection between the coffee producer and financial institutions to increase access of credit to coffee producer. When there is high access of credit the farmer can buy different inputs like fertilizer, pesticides and technology which increase coffee production and income of coffee producers.

v. Empowering Households with information and education: Creating and expanding awareness among the population and policy makers about climate variability, its impact on their livelihood, causes and consequences by providing reliable and up to-to-date information to take appropriate adaptive measures.

vi. Improve farmers' "access to affordable credit and support the growth and development of credit institutions and it is important to consider its accessibility to farmers nearby their locality and of other income generating activities to increase their ability and flexibility for both short- and long-term adaptation measures.

vii. Furthermore, there is a necessity to incorporate broadening of agricultural production, enhancing agriculture inputs and supporting farmers to use their indigenous knowledge in joint with modern agriculture technology to strengthen local adaptation to climate change.

viii. Government as well as other stakeholders working around agriculture sector, should work together to provide trainings and other agriculture extension services that would provide farmers with adequate knowledge on good practices and maintenance of coffee farm as well the environment in general.

\section{References}

[1] Pendergrast, M. (1999) The Provision of Incentives in coffee producing Firms, journal of Economics literature.

[2] Watson, K., \& Achinelli, M. 2008 Context and contingency: the coffee crisis for conventional small - scale coffee farmers in BrazilThe Geographical Journal 223-234.

[3] Fernie L. M. (1966) Some impressions of coffee in Ethiopia. Kenya Coffee 31: 115-121.

[4] Bayetta, B. 2001. Arabica coffee breeding for yield and resistance to coffee berry disease (Colletotricum kahawah sp.), Doctoral Thesis, Imperial College Wye University, London.

[5] FAO (1987) World crop and livestock 1984-1985. Food and Agricultural Organisation of the United Nations, Rome. 
[6] Höfner W. (1987) Nährstoffstatus der Böden in den Kaffeeanbaugebieten Äthiopien. In: 20 Jahre Agrarforschung des Tropeninstituts in Äthiopien, ed. H. E. Matter and A. Westpal. Tropeninstitut Giessen, Pp. 55-56.

[7] Gemechu D. (1977) Aspects of climate and water budget in Ethiopia. Addis Ababa, University Press.

[8] Demel T., Ababu A., Getahun M. and Mehari E. (1998) Study on forest coffee conservation. Coffee Improvement Project, Ethiopia.

[9] Woods M. T. D. (2003) Project Report on Ethiopia, Houses of the Oreachatas, Joint Committee on foreign affairs, July 2003.

[10] McMillan, M., Assefa Tigneh, Yohannes Agnofir, Kibre Moges and Amdissa Teshome (2003). ETHIOPIA: Trade and Transformation Challenges. Agriculture and Trade Diagnostic Trade Integration Study. Annex 8, Volume 2, Addis Abeba, Ethiopia.
[11] Oxfam (2002). Crises in the Birthplace of Coffee. Oxfam International Research Paper.

[12] Kothari, C. (2004). Quantitative Techniques, 2nded. New Delhi: Vikas Publishing House Pvt.Ltd.India.

[13] Gujarati, D. N. (2004). sic Econometrics. Ba 3rd Edition. New York, McGraw-Hill.

[14] Greene, J. \& Villanueva, D. (1991). Private Investment in Developing Countries: An Empirical Analysis. IMF Staff Papers, 38 (1).

[15] Alemu Shumiye.(2007). Determinants of Food Insecurity in Rural Households in Tehuludere Woreda, South Wollo Zone of Amahra Region: unpublished Master Thesis, Department of Statistics, Addis Ababa University, Ethiopia.

[16] Paulos D. (1994) Mineral fertilisation of coffee in Ethiopia. Institute of Agricultural Research, AddisAbaba. 107. 3-15 August 1999, Addis Ababa, Ethiopia. 